\title{
Nonfunctional pacemaker leads: To remove or not to remove, that is the multifactorial question
}

\author{
Carol W. Chen, MD, and Pavan Atluri, MD
}

\footnotetext{
From the Division of Cardiovascular Surgery, Department of Surgery, University of Pennsylvania, Philadelphia, $\mathrm{Pa}$.

Disclosures: Authors have nothing to disclose with regard to commercial support.

Received for publication June 24, 2016; accepted for publication June 25, 2016; available ahead of print July 27, 2016.

Address for reprints: Pavan Atluri, MD, Division of Cardiovascular Surgery, Department of Surgery, University of Pennsylvania, Silverstein 6, 3400 Spruce St, Philadelphia, PA 19104 (E-mail: Pavan.atluri@uphs.upenn.edu). J Thorac Cardiovasc Surg 2016;152:e89-90 $0022-5223 / \$ 36.00$

Copyright (C) 2016 by The American Association for Thoracic Surgery http://dx.doi.org/10.1016/j.jtcvs.2016.06.052
}

In their stimulating case report, Chen and colleagues ${ }^{1}$ describe unusual but notable sequelae after pacemaker laser lead extraction. As with any procedure, particularly those related to the cardiovascular system, a risk-to-benefit ratio must be carefully analyzed before the intervention. The report illustrates potential complications that should be thoroughly appreciated by all electrophysiologists and cardiac surgeons as more long-term pacing leads become nonfunctional or infected.

Although simple in concept, transvenous lead extraction is associated with a risk of significant complications, including arteriovenous fistula formation, as eloquently illustrated in this report. Among the methods for lead extraction, use of a laser extraction technique has become commonplace for electrophysiologists, often without surgical backup (Figure 1). Although laserassisted extraction is highly efficacious, it is an independent predictor of major morbidity among lead extraction techniques. $^{2}$ In the randomized prospective Pacing Lead Extraction with the Excimer Sheath trial, ${ }^{3}$ the rate of major complication with laser-assisted extraction was roughly $2 \%$, with 1 death and 3 other life-threatening events among 153 patients. The results demonstrate fairly low concomitant morbidity and mortality, yet the focus should remain on further minimizing the risk profile of the procedure.

More specific to the current case report, female gender and implant duration are risk factors for major complications and should factor strongly into the decision for lead removal. $^{2,4,5}$ After 20 years and multiple revisions, the degree of fibrotic attachment of the lead to the venous lumen was likely to be extensive in this patient. Opposing factors cloud the decision-making process in this case. Removal of a noninfected, nonfunctional lead is assigned Level of Evidence $\mathrm{C}$ because it is often safe to abandon a failed lead that is not arrhythmogenic or causing other immediate threats to the patient. ${ }^{2}$ However, this patient's young age argued against leaving the lead in place without

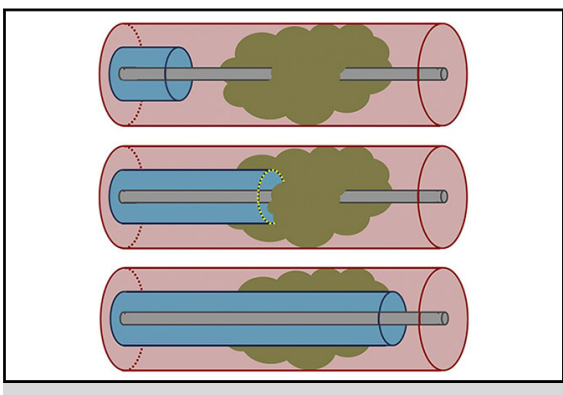

The laser sheath delivers energy to the free lead from intravenous scar tissue as it advances.

\section{Central Message}

Transvenous lead extraction is not always straightforward, and extra precautionsperhaps with additional preoperative and intraoperative evaluations-should be taken in high-risk patients.

See Article page e85.

attempting removal because she was likely to require additional leads during the next several decades.

Also germane to the discussion is the management of the innominate artery-to-vein fistula. Similar iatrogenic
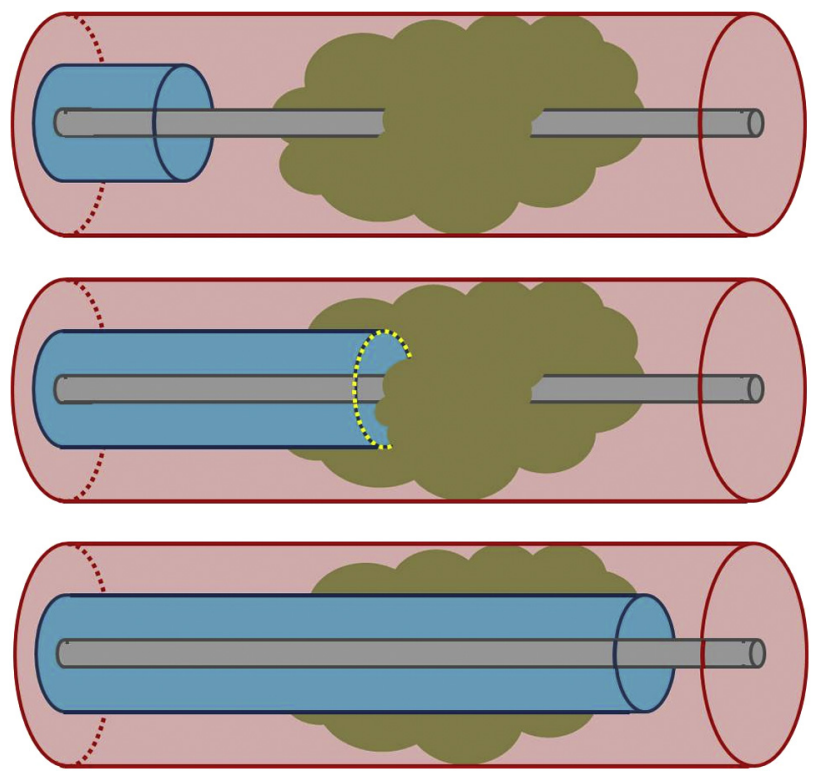

FIGURE 1. Diagram of laser sheath-assisted removal of lead. The laser sheath is advanced over the lead (top). Energy is delivered to free the lead from intraluminal fibrotic tissue (middle). The sheath continues to advance over the freed lead (bottom). 
arteriovenous fistulas from the placement of central lines and pacemakers are increasingly being treated with minimally invasive techniques, such as percutaneous coil embolization $^{6}$ and endovascular stenting, ${ }^{7}$ with good results. Yet, given the medial location of the fistula in this report and the need for tricuspid valve intervention, open repair via sternotomy as performed by the authors seemed to be the most appropriate approach.

Transvenous lead extraction is not always straightforward, and extra precautions-perhaps with additional preoperative and intraoperative evaluations-should be taken in patients who are likely to present a difficult procedure. A thorough understanding of anatomic relationships and potential complications can minimize adverse outcomes with this complex procedure. With the increasing prevalence of cardiovascular implantable electronic devices, cardiac surgeons will continue to see unique presentations of rare but critical complications associated with lead removal.

\section{References}

1. Chen PC, Greenberg S, Mathuria N, Livesay JJ. Operative repair of iatrogenic innominate artery to left innominate vein arteriovenous fistula after pacemaker laser lead extraction. J Thorac Cardiovasc Surg. 2016;152:e85-7.

2. Wilkoff BL, Love CJ, Byrd CL, Bongiorni MG, Carrillo RG, Crossley GH III, et al. Transvenous lead extraction: heart rhythm society expert consensus on facilities, training, indications, and patient management: this document was endorsed by the American Heart Association (AHA). Heart Rhythm. 2009;6:1085-104.

3. Wilkoff BL, Byrd CL, Love CJ, Hyes DL, Sellers TD, Schaerf R, et al. Pacemaker lead extraction with the laser sheath: results of the Pacing Lead Extraction with the Excimer Sheath (PLEXES) trial. J Am Coll Cardiol. 1999;33:1671-6.

4. Byrd CL, Wilkoff BL, Love CJ, Sellers TD, Reiser C. Clinical study of the laser sheath for lead extraction: the total experience in the United States. Pacing Clin Electrophysiol. 2002;25:804-8.

5. Pierce M, Pratap B, Pamidimukala C, Bastawrose J, Lingannan A, Panneerselvam N, et al. Female gender, laser sheath use and operator skill drive the success and complication rates of cardiac device lead extraction: an Acap Registry analysis. J Am Coll Cardiol. 2014;63:A381.

6. Anguera I, Real I, Morales M, Vazquez F, Montana X, Pare C. Left internal mammary artery to innominate vein fistula complicating pacemaker insertion. Treatment with endovascular transarterial coil embolization. J Cardiovasc Surg (Torino). 1999;40:523-5.

7. Hilfiker PR, Razavi MK, Kee ST, Sze DY, Semba CP, Dake MD. Stent-graft therapy for subclavian artery aneurysms and fistulas: single-center mid-term results. J Vasc Interv Radiol. 2000;11:578-84. 